\title{
Reseña: Miradas colectivas sobre la participación: sugerencias para la práctica / María Mercedes Oraisón; María Bernabela Pelli. - 1a ed. - Resistencia: Universidad Nacional del Nordeste. Centro de Estudios Sociales, 2020.
}

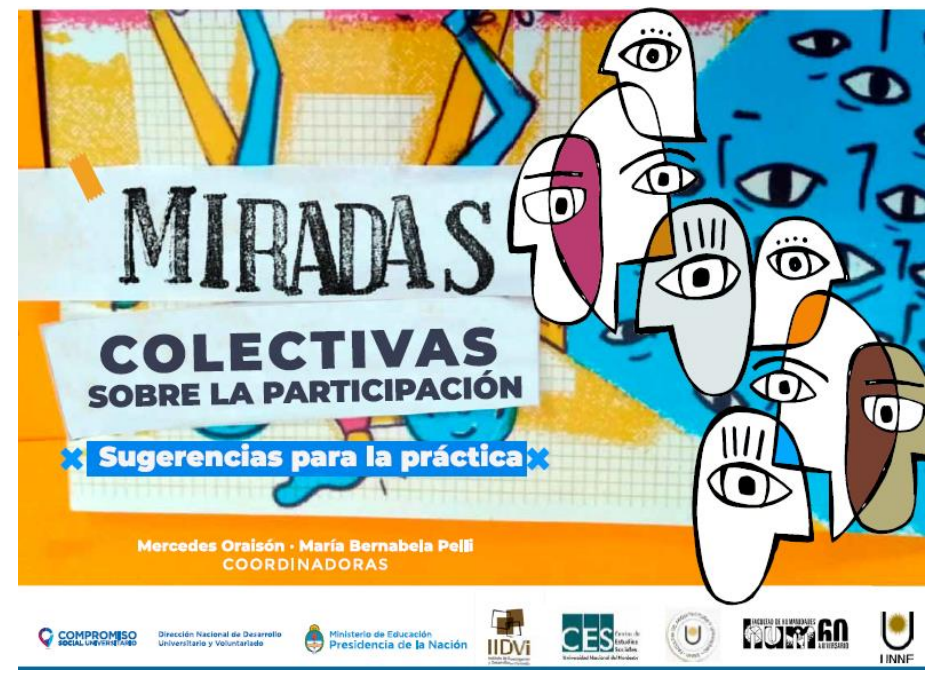

Miradas colectivas sobre la participación: sugerencias para la práctica es una publicación que propone, en su esencia, una mirada plural sobre y desde las experiencias participativas de las organizaciones sociales, dando cuenta de los procesos de construcción y desarrollo de estos proyectos hacia adentro, $y$, a la vez, visibilizando la importancia que tiene su vinculación con el resto de la vida pública, social y política. Es un manual que describe cómo se articulan los mecanismos de colaboración entre las organizaciones comunitarias y los estamentos del Estado, producto tangible del proceso que describe la práctica conjunta, territorial y social en la que la Universidad es, en este caso, una protagonista más en las búsquedas que a diario realizan los sectores populares. Este material fue construido en conjunto con el proyecto de voluntariado universitario Gestión participativa, seleccionado en la convocatoria 2017 del programa Compromiso Social Universitario de la Secretaría de Políticas Universitarias, y promovido por dos equipos universitarios: el Centro de Estudios

\footnotetext{
${ }^{1}$ Comunicador Comunitario. Referente de la Asociación Civil Integración Solidaria (Corrientes). Email: enlarreta@gmail.com

${ }^{2}$ Técnico en Periodismo (Facultad de Humanidades UNNE), Referente de la Asociación Civil Integración Solidaria (Corrientes) Email: marianoadrian.leiva@gmail.com
} 
Sociales y un equipo de investigación del Instituto de Investigación y Desarrollo en Vivienda de la Facultad de Arquitectura y Urbanismo. Contó también con la activa e indispensable participación de vecinos y vecinas, quienes nutrieron con sus experiencias y saberes el contenido del mismo. La contribución de la Unne, con recursos económicos y humanos (conocimiento, tiempo, trabajo), ha sido fundamental para la concreción del proyecto. Pero lo más valioso, lo que enriquece al manual, es la participación, "caminar los barrios", el intercambio con los y las referentes de las comunidades con las que se elaboró esta publicación. Esa reciprocidad, esa "comunicación", es la que determinará que esta publicación pueda transformarse en una referencia a la hora de pensar, repensar, cuestionar y debatir sobre las prácticas y sugerencias allí abordadas. Como resultado de este intercambio, de esta contaminación positiva entre los actores participantes, el manual emplea un lenguaje común, territorial y práctico, pero a la vez propende a la reflexión. Miradas colectivas sobre la participación: sugerencias para la práctica se estructura en torno a cuatro ejes que atraviesan a toda organización social que opere en el territorio: comunicación, gestión, procesos de organización y sustentabilidad. La comunicación aquí es abordada con una mirada comunitaria, observando el contenido sin descuidar las formas, subrayando su importancia a la hora de informar, pero también como cimiento necesario donde apoyar los procesos de construcción colectiva. Siendo la gestión otro de los momentos más álgidos en el accionar de las organizaciones, el manual remarca la relación de estas con un actor social de mayor envergadura como es el Estado, e incluye la articulación con otras organizaciones, referentes e instituciones no gubernamentales, lo que les permite potenciar sus esfuerzos como también sus logros. Sobre los procesos de organización, quizás uno de los escollos más duros de todo espacio que se precie de participativo y organizado, el manual revisa aquellas prácticas que atentan contra la continuidad de los procesos organizativos, analizando algunas experiencias facilitadoras o que ayuden a sostenerse en el tiempo. Por último, el texto indaga sobre la sustentabilidad de las organizaciones en el tiempo y el marco político institucional en el que se tejen las relaciones, logrando de ese modo aquello por lo cual surgen dichos espacios y que no es otra cosa que lograr incidir en las políticas públicas adoptadas por el Estado. Cada página de este material, por lo tanto, refleja la fluidez lograda entre lo académico y aquellos conocimientos que circulan en el territorio, con calidez humana y profesional, proponiendo un camino, una manera, entre tantas otras. Las trayectorias y las experiencias de las organizaciones se van ampliando y modificando, y este texto será el testimonio de lo que los participantes pudieron aportar en este momento específico de su historia. Desde las organizaciones sociales, celebramos esta postura proactiva de la Universidad, siendo parte, reconociendo e integrándose a las dinámicas propias del trabajo de los colectivos comunitarios. Entendemos también que estas experiencias de colaboración concreta y 
articulada de las universidades en el territorio y a la par con las organizaciones, no abundan. Esperamos, entonces, que esto sea un punto de partida que nos posibilite transitar un camino de aperturas hacia la proyección de nuevos escenarios de reflexión y análisis, y que esta lógica de contribución recíproca pueda replicarse, ampliarse y profundizarse en el tiempo. 